\title{
SLEGS ROBOT TABANLI YÜRÜME ENGELLİ ARACI TASARIMI*
}

$* * *$

\author{
WALKING DISABLED VEHICLE DESIGN BASED SLEGS ROBOT
}

\begin{abstract}
$\ddot{O} \mathbf{z}$
Giderek yaşlanan dünya nüfusuna paralel olarak engelli insan saylsı da her geçen yıl artmaktadır. Engelli bireyler dünya nüfusunun yaklaşı \%15'lik bir kismını teşkil etmekte ve bu sayı yaşlılık ve hastalıkların artmast ile giderek artış göstermektedir. Engelli bireyler içinde yüksek oranda yer alan yürüme engelli bireylerin, özellikle merdiven gibi engebeli yerlerde rahat hareket etmeleri yaşam kaliteleri açısından oldukça önemlidir. Bu bağlamda geliştirilmiş araçlar bulunmakta ve satılmaktadır. Fakat bunlar hem pahalı hem de bir refakatçi gerektiren ürünlerdir. Yürüme engelli bireyler için merdiven gibi yerlerde rahat hareket etmelerini sağlayacak araç tasarım ve üretim amacı ile bu çalışma gerçekleştirilmiştir. SLEGS robot olarak bilinen tekerlek teknolojisi, Fusion 360 programı ile yürüme engelli araçları için tasarlanmıştır. Engebeli yerlerde ' $S$ ' şekline normal zeminlerde ise ' $O$ ' şekline dönüşebilen tekerlekler engelli aracının her alanda rahatllkla hareket etmesini sağlayabilecektir. Tekerleklerin hareketi için Servo Motorlar ve Arduino Nano kullanılmıştır. Bir prototip üzerinde önerilen tasarım gösterilmiştir. Önerilen ürünün yürüme engelli bireyler için hem yerli hem de ucuz bir ürün olarak rahatlıkla kullanılabileceği düşünülmektedir.
\end{abstract}

Anahtar Kelimeler: S Bacak, SLEGS tekerlek, Yürüme engelli, Arduino, Fusion 360.

\begin{abstract}
Parallel to the aging world population, the number of people with disabilities is increasing every year. Individuals with disabilities make up about $15 \%$ of the world's population and this number is increasing with increasing age and diseases. It is very important for people with walking disabled, which are high among disabled people, to move freely in rugged places such as stairs. In this context, improved vehicles are available and sold. However, these are both expensive and require a companion. This study was carried out for walking disabled individuals for the purpose of vehicle design and production which will enable them to move freely in places such as stairs. The wheel technology, known as the SLEGS robot, is designed for vehicles with walking disabilities with the Fusion 360 program. Wheels that can turn into ' $S$ ' shape in rugged areas and ' $O$ ' shape on normal floors will enable the disabled vehicle to move easily in all areas. Servo Motors and Arduino Nano are used for the movement of the wheels. The proposed design on a prototype is shown. It is thought that the proposed product can be easily used both as a domestic and cheap product for people with walking disabilities.
\end{abstract}

Keywords: S Leg, SLEGS wheel, Walking Disabled, Arduino, Fusion 360.

\section{GíRiş}

\footnotetext{
${ }^{*}$ Bu çalışma, Tübitak 2204 kapsamında hazırlanan bir projenin geliştirilmiş nihai halidir.

* Dr., Karşıyaka Kız Teknik ve Meslek Lisesi Sivas, Bilişim Teknolojileri Bölümü, mesutbiyan@ gmail.com ORCID: 0000-0002-7503-2977
} 
Yaklaşık 6,5 milyar insanın yaşadığı dünyamızda \% 8,5 (617 milyon) 65 yaş ve üstü bireyler bulunmaktadır. Bu yaşlı nüfusun teknoloji ve sağlıkta yaşanan gelişmeler de düşünüldüğünde 2050 yılına kadar 1,6 milyara olacağı ve bu oranın nüfusun \% 17'si olacağ 1 tahmin edilmektedir. (Tandoğan, 2017).

Yaşlı nüfusunun yoğun olduğu dünya nüfusunda engelli bireyler ise yaklaşı \% $\% 15$ 'lik bir kısmını teşkil etmektedir. Nüfusun giderek yaşlanması ve hastalıkların artması düşünüldügünde engelli nüfusunun da artış göstereceği tahmin edilmektedir. Dünya Sağlık Örgütü (WHO) doğrudan ya da dolaylı dünya nüfusunun \%25'inin engellilik durumuyla karşı karşıya kalabileceğini düşünmektedir (Tandoğan, 2017).

Türkiye'de ise engelli insanların oranı yaklaşık olarak nüfusun yaklaşık olarak \%13'ünü oluşturmaktadır. Her ne kadar engelli insan sayısı fazla olsa da maalesef ülkemiz açısından çevresel imkânlar engelliler için elverişli değildir. Özellikle binalar, caddeler ve merdivenler gibi yerlerde özellikle yürüme engelli insanlar ciddi problemlerle karşılaşmaktadırlar. Bazı insanlar doğuştan bazıları ise daha sonraları bir takım olaylar sonucunda engelli kalabilirler ve hayatlarını devam ettirmek için bazı özel ekipmanlar (koltuk değneği, tekerlekli sandalye vb.) onlar için oldukça önemli olabilir. Bu nedenle plânlama ve tasarım sürecinde söz konusu bireyler ile ekipmanlar göz ardı edilmemeli; bunun yanında da yeni teknolojik araç ve cihazlar geliştirilmelidir (Feyzioğlu, 2013).

Altınok ve Kars (2010), engelli nüfusun içerisinde en fazla yürüme engellilerin olduğunu ve bu insanların hem çevrelerinde hem de konut gibi yerlerde hareket alanının oldukça sınırlı olduğu, yetersiz kaldığını belirtmektedir.

Her ne kadar çevre düzenlemeleri yapılsa da engelli bireylerin özellikle tekerlekli araba kullanan bireylerin merdiven inme ve çıkma gibi durumlarda yardıma ihtiyaç duymadan ihtiyaçlarını karşılayabilecekleri teknolojiye ihtiyaçları vardır.

Literatürde engelli bireylerle ilgili birçok çalışmaya rastlanılmıştır. Turan (2005), güneş enerjili tekerlekli araba tasarımı gerçekleştirmiştir. Çınar ve Erdem (2008), ülkemizde yaşayan engelli bireylerin (tekerlekli sandalye kullanıcıları) yaşam hakkı kavramı çerçevesinde konut mekân donatı elemanları ve mobilya kullanımına yönelik hareket özgürlüklerini tespit etmişlerdir. Sirel vd (2012), Çukurova Üniversitesi yerleşkesi açık alanlarının fiziksel engelliler bakımından ulaşılabilirliği incelemişlerdir. Bekçi (2012), Bartın ilinde gerçekleştirdiği çalışmasında ulaşım akslarının fiziksel engellilerin kullanımı için oldukça problemli olduğu ve bundan dolayı birçok fiziksel engellinin bu alanları kullanırken ciddi sorunlarla karşılaştığı, hatta kullanamadığını tespit edilmiştir. True ve Türel (2013), yapılı fiziksel çevrelerin sahip olduğu yetersizlikler ve bu yetersizliklerden kaynaklanan sınırlamalar nedeniyle engelliler açısından önemli bir sorun haline dönüştüğü belirlenmiştir. Çınar, Arslan, Öztürk ve Bülbül (2015), kamu binalarının kullanımında tekerlekli sandalye kullanıcıları ve görme engelli bireylerin ciddi sorunlar yaşadığı, memnuniyet durumlarının ise son derece düşük olduğu tespit edilmiştir. Sümbül ve Yakut (2016) yürüme engelli bireyler için pedaldan kumandalı dikiş makinelerinin kumanda bileklik sistemi ile kontrolünü gerçekleştirmişlerdir. Öztabak (2017), engelli bireylerin yaşamdan beklentilerini, hayallerini, korkularını, hoşlandıkları faaliyetleri, gelecekle ilgili düşüncelerini belirlemişlerdir. Kırdı ve Keser (2019), yaşlılarda kullanılabilecek ergonomik tekerlekli sandalye teknolojilerini incelemişlerdir. Saplığlu ve Ünal (2019), ileride oluşturulacak akıllı ulaşım ve kavşak sistemleri ile donatılabilecek, yürüme engelli kişiler için güvenli, geometrisi uygun ve rahat kullanabilecekleri güzergâhların öncelikli olarak nereler olması gerektiğini belirtmiştir.

Literatüre bakıldığı zaman genellikle engellilerin günlük yaşamdaki çevre koşulları, beklentileri gibi konuların çalışıldığ 1 görülmektedir. Her ne kadar görme engelliler için tasarlanan 
gözlük ve baston çalışmaları olsa da özellikle yürüme engelli bireyler için tasarım çalışmasının olmadığı görülmektedir.

Fakat firmaların yürüme engelliler için geliştirmiş oldukları engelli arabalar oldukları görülmüştür. İncelenen firma ürünlerinin refakatçi yardımı ile engellilerin merdiven gibi yerlerde zorlanmadan inme ve çıkmalarını sağlayan engelli araçları üretip sattıkları görülmüştür. Bu araçların en büyük dezavantajı engelli bireylerin bir refakatçiye ihtiyaç duymalarıdır. Bir diğer önemli sorun ise bu araçların ciddi maliyetlerinin olduğu ve engelli bireylerin bu maliyetleri karşılamada güçlük yaşayabilecekleridir. Bu firmalar ve ürünleri Tablo 1'de gösterilmiştir.

Tablo 1. Yürüme engelli bireyler için üretilen cihazlar ve fiyatları

\begin{tabular}{|c|c|}
\hline Ürün Adı & Fiyatı \\
\hline Poylin P315 & $14,000 \mathrm{TL}$ \\
\hline SHERPA N902 & $20,000 \mathrm{TL}$ \\
\hline Mor Medikal & $9,300 \mathrm{TL}$ \\
\hline Yack-N962 & $15,700 \mathrm{TL}$ \\
\hline
\end{tabular}

Tablo 1 'de görüldüğü gibi yürüme engelli bireylerin özellikle merdiven gibi yerlerde inip çıkmaları için geliştirilmiş cihazlar olsa da bunlar hem ithal hem de pahalı ürünler olduğundan dolayı engelliler zorluk yaşamaktadırlar. Bu yüzde teknolojik, yerli ve uygun maliyetli bir araç tasarımına ihtiyaç olduğu görülmektedir. Bu çalışma bu amaçla geliştirilmiştir.

Çalışma sonucunda; yerli, teknolojik ve ucuz bir cihazı ülkemizin üretimi ve pazarlaması yönündeki gelişmelere zemin oluşturacağı düşünülmektedir.

\section{SLEGS ROBOT}

Zaman geçtikçe tekerlek ile hareket eden robotlarda özellikle performans açısından bazı dezavantajlara sahip olduğu tespit edilmiştir. Engebeli alanlarda özellikle de merdiven gibi yerlerde tırmanma ya da çıkma gibi hareketlerin yapılamaması bu dezavantajlarından biridir. Robot teknolojisinin gelişmesi ile her geçen gün yeni tasarımlar ortaya çıkmaktadır. Bunda özellikle robotların artık yaşantımızda daha fazla yer almasının oldukça önemli bir payı vardır. SLEGS robot da bu tasarımlardan biridir. SLEGS robot, örümcek bacak şeklinden ilham alınarak ortaya çıkmıştır. $\mathrm{Bu}$ tasarım oldukça detaylı ve uzun süren çalışmalar ve araştırmalar neticesinde bulunmuş önemli ARGE projesidir. Literatür çalışmalarında olmayan bu tasarım için patent çalışmalarının olduğu bilinmektedir. SLEGS robotun sahip olduğu kendisine has bacaklar birçok farklı alanda ve amaçla kullanılmaya uygundur (Soygüder, 2018).

SLEGS Robot birbirine dönüşebilen iki farklı bacak şekline sahiptir. $\mathrm{Bu}$ bacaklar karşılaştıkları yol ve engebe durumuna göre otomatik olarak şekil değiştirir. Yol düz ve normal ise "O" şeklinde olur, yol engebeli ve merdiven şeklinde ise bacaklar "S" şekline dönüşür. Her bir bacak 3 adet Servo motor ile hareket edebilmektedirler (Soygüder, 2018). 


\section{TASARIM}

Fusion 360, 3 boyutlu modeller yapabileceğiniz bu modelleri teste sokabileceğiniz ve modelleri anime edip çıktı edinebileceğiniz bir modelleme programıdır. Bulut tabanlı olması ve öğrenciler ile eğitimcilere ücretsiz sunulması da programın önemli avantajlarıdır. Bu yüzden bu çalışmada da Fusion 360 programı tercih edilmiştir. Fusion 360 programında SLEG tekerlek tasarımları Şekil 1' de görüldüğü gibi yapılmıştır. Yapılan tasarımlar Ultimaker 2+ üç boyutlu yazıcısı kullanılarak çıktı alınmıştır.

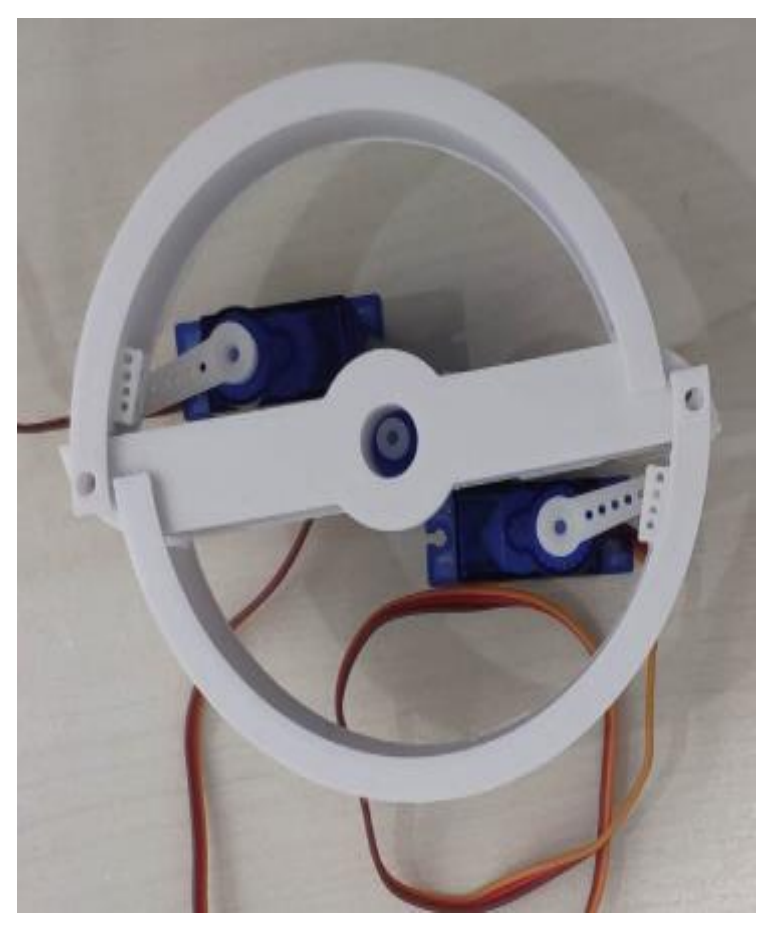

a) SLEGS robotun bacağının "O” şekli

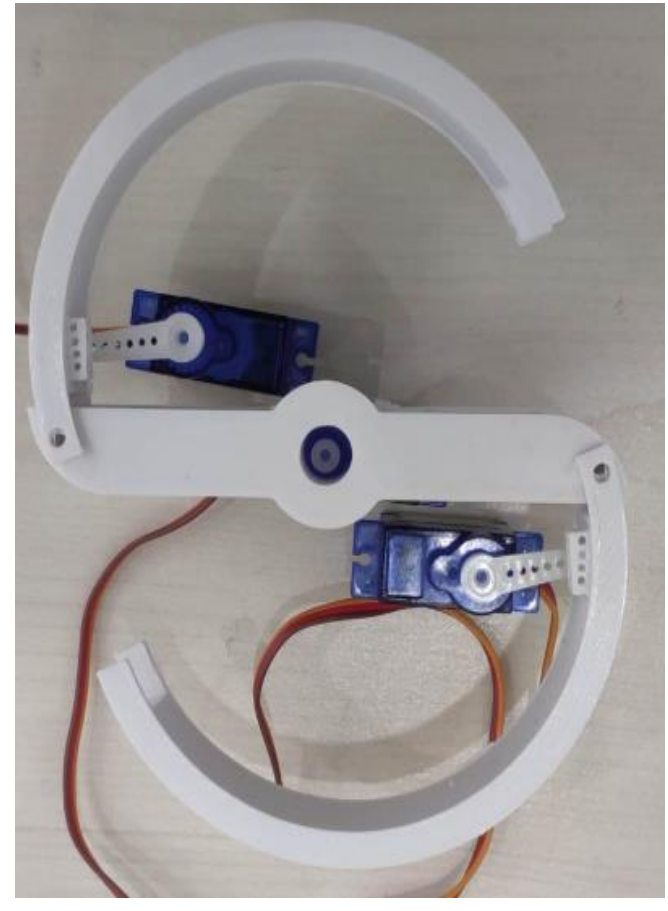

b) SLEGS robotun bacağının "S" şekli

Şekil 1. SLEGS bacakların 3 boyutlu yazıcıdan alınan çıktısı

Örnek bir prototip oluşturmak amaciyla tasarlanan ve üretilen tekerlekler Fusion 360 programı kullanılarak yürüme engellilerin kullandığı tekerlekli arabaya monte edilmiştir. Şekil 2'de görüldüğü gibi monte edilen SLEG tekerlekler sayesinde tekerlekli sandalye engebeli yerlerde tekerleklerin 'S' olması sayesinde daha rahat hareket edebilecektir. Şekil 2'nin (b) kısmında gösterildiği gibi kullanıcı istediği bir anda tekerleklerin ' $S$ ' konumuna geçmesini sağlayabilir. 

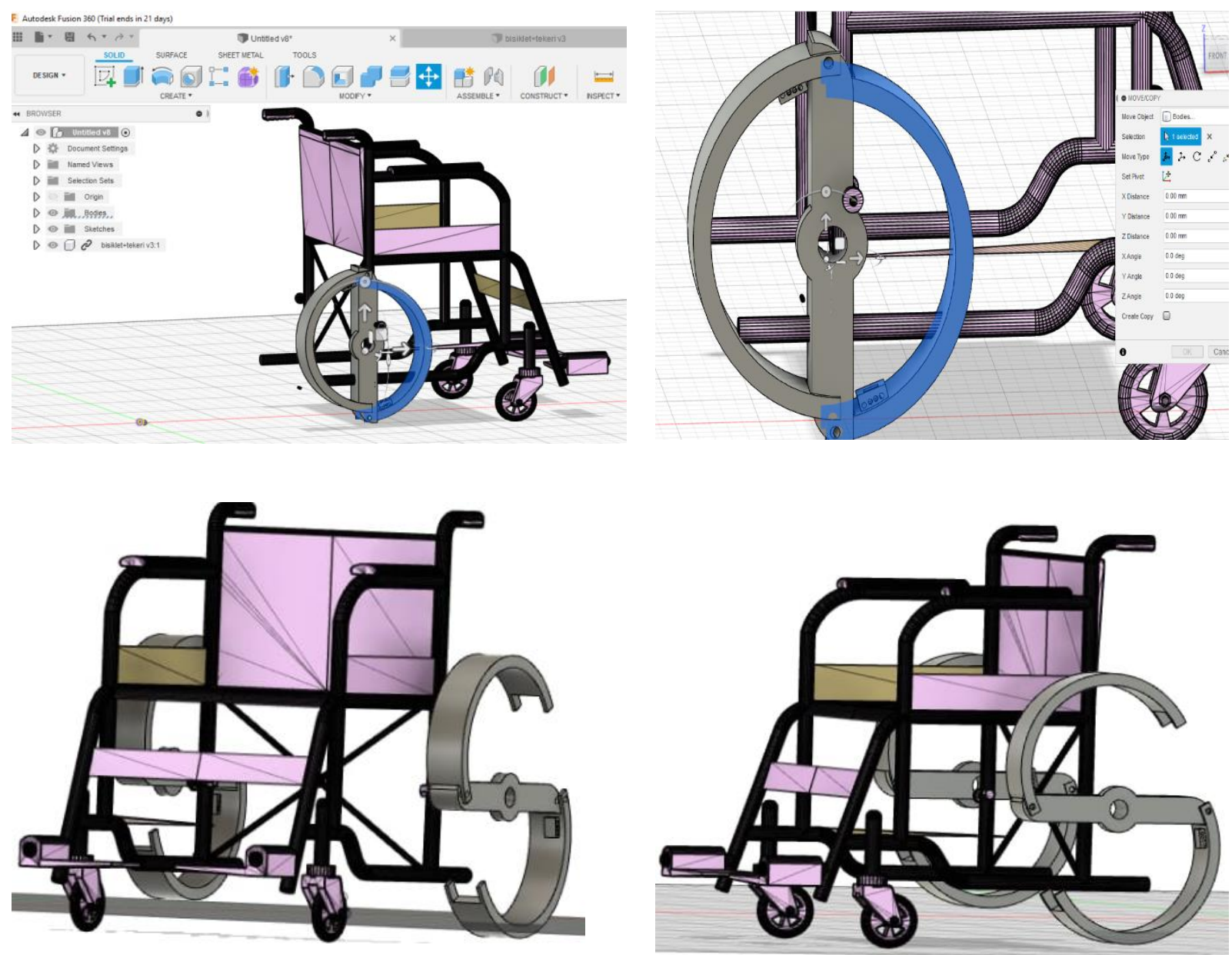

Şekil 2. SLEGS bacakların Fusion 360 ile yürüme engelli aracına monte edilmesi

Fusion 360 programı ile tasarlanan ürünün prototipini oluşturmak amaciyla tasarlanan ürün Ultimate 2+ yazıcısı kullanılarak çıktı alınmıştır. Prototip sayesinde SLEGS tekerleklerin çalışma şekli daha rahat anlaşılabilecektir. Prototipin çalışması için tekerleklerin konum değişimleri Arduino Nano ve Servo motorlar ile kontrol edilmektedir. Kullanıcının sistemi harekete geçirmesi ile Arduino üzerinden servolara açısal bilgiler yollanmakta bu sayede tekerleklerin şekil değiştirmesi sağlanmaktadır.

3 boyutlu yazıcıdan çıkan prototip Cura adlı programda dilimlenmiştir. Ve programda ki prototipin ayarları Şekil 3'de verilmiştir. Parametreler birkaç kez çıktı alınarak denemeler sonucunda nihai halini almıştır. 
Uluslararası Yönetim Bilişim Sistemleri ve Bilgisayar Bilimleri Dergisi, 2020, 4(1):42-51

Makale Türü: Araştırma Makalesi
International Journal of Management Information Systems and Computer Science, 2020, 4(1):42-51 Paper Type: Research Paper

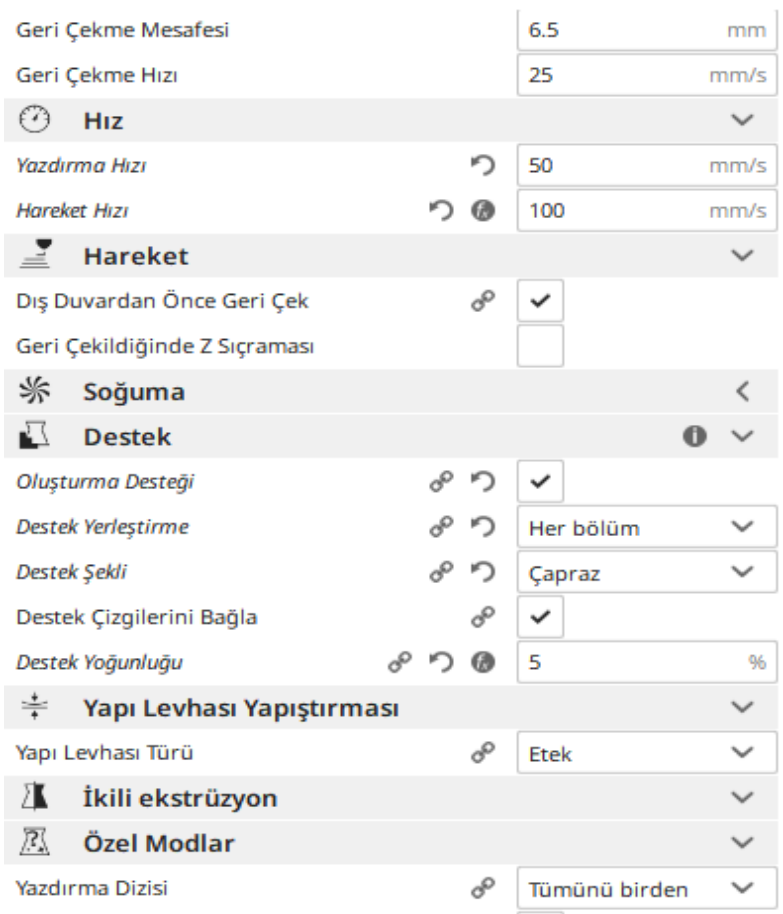

\begin{tabular}{|c|c|c|c|}
\hline$=$ Kalite & & & $\checkmark$ \\
\hline Katman Yükseklig̈i & $8^{\circ}$ & 0.2 & $\mathrm{~mm}$ \\
\hline$\triangle$ Kovan & & & $\vee$ \\
\hline Duvar Kalınlığı & & 1.2 & $\mathrm{~mm}$ \\
\hline Dış Duvar Sürme Mesafesi & & 0.0 & $\mathrm{~mm}$ \\
\hline Üst/Alt Kalınlık & & 0.8 & $\mathrm{~mm}$ \\
\hline Dolgu & & & $\vee$ \\
\hline Dolgu Yoḡunluḡu & $\eta$ & 40 & $\%$ \\
\hline Aşamalı Dolgu Basamakları & & 0 & \\
\hline\|\|$\|$ Malzeme & & & $<$ \\
\hline Yazdırma Sıcaklığı & & 200 & ${ }^{\circ} \mathrm{C}$ \\
\hline İlk Katman Yazdırma Sıcaklığı & & 200 & ${ }^{\circ} \mathrm{C}$ \\
\hline İlk Yazdırma Sıcaklığı & & 200 & ${ }^{\circ} \mathrm{C}$ \\
\hline Son Yazdırma Sıcaklığı & & 200 & ${ }^{\circ} \mathrm{C}$ \\
\hline Yapı Levhası Sıcaklığı & $\infty^{\circ}$ & 60 & ${ }^{\circ} \mathrm{C}$ \\
\hline Akış & & 100 & $\%$ \\
\hline İlk Direk Akışı & & 100 & $\%$ \\
\hline Geri Çekmeyi Etkinleştir & & $\checkmark$ & \\
\hline Katman Değişimindeki Geri Çekme & & & \\
\hline Geri Çekme Mesafesi & & 6.5 & $\mathrm{~mm}$ \\
\hline
\end{tabular}

Şekil 3. Cura yazılımda dilimleme için ayarlanan parametreler.

Ürünün nihai hali ise Şekil 4'de verilmiştir. Ardunio ve servo motorlar ile SLEGS tekerlekler yürüme engelli arabasına monte edilmiş ve ürünün prototipi oluşturulmuştur.

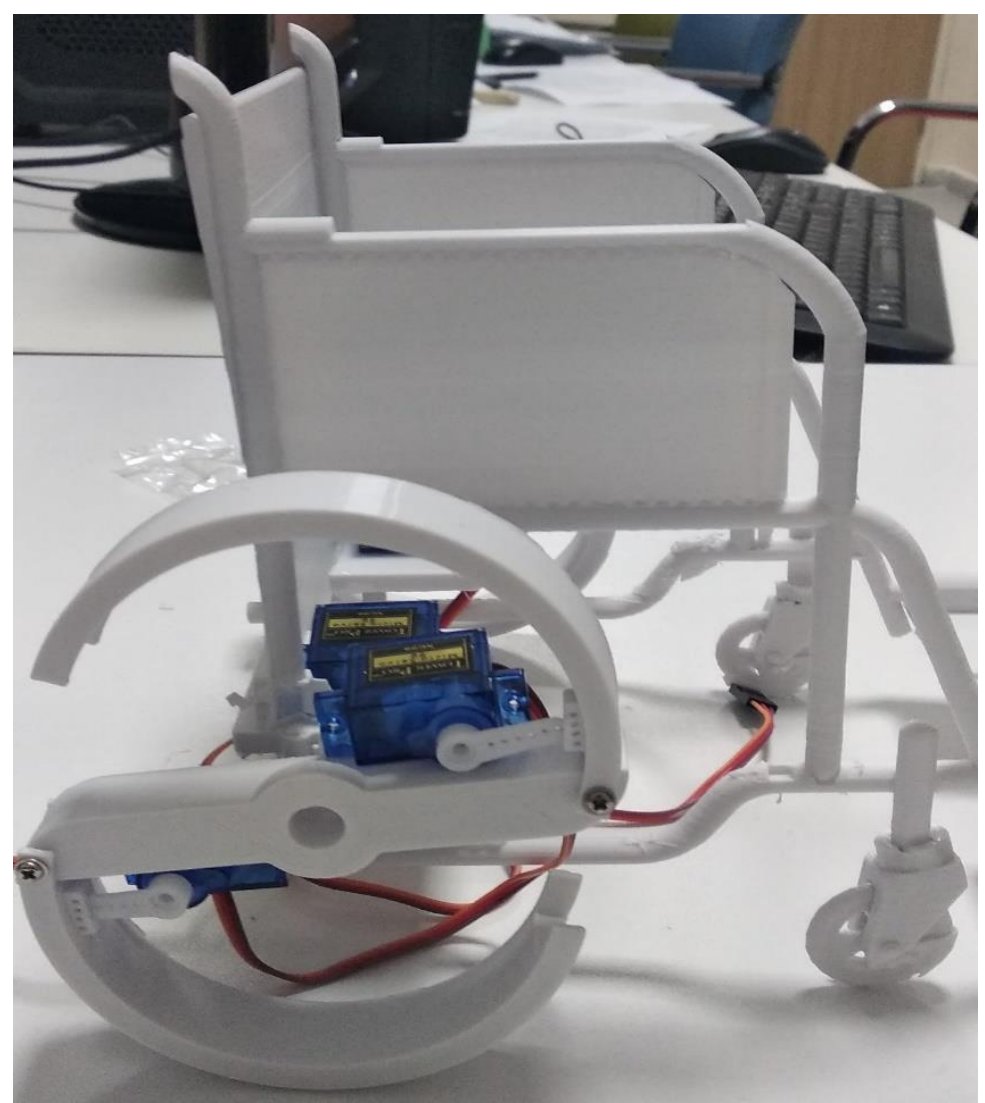

Şekil 4. SLEGS yürüme engelli arabası nihai ürün 
Çalışmada prototip oluşturmak için kullanılan malzemeler ve fiyatları Tablo 2'de verilmiştir.

Tablo 2. SLEGS yürüme engelli arabası prototip için malzeme ve fiyat listesi

\begin{tabular}{|c|c|c|c|}
\hline Malzeme Adı & Adet & Adet Fiyatı & Toplam Fiyat \\
\hline Servo Motor & 6 & $10 \mathrm{TL}$ & 60 TL \\
\hline Arduino Nano & 1 & $20 \mathrm{TL}$ & 20 TL \\
\hline Pil (1.5v) & 4 & $2 \mathrm{TL}$ \\
\hline Slegs Özellikli & 2 & $40 \mathrm{TL}$ & $80 \mathrm{TL}$ \\
\hline Tekerlek Basımı & 40 & & \\
\hline Kablolar & & $0,25 \mathrm{TL}$ & $10 \mathrm{TL}$ \\
\hline Toplam & & $\mathbf{1 7 8} \mathbf{~ T L}$ & \\
\hline
\end{tabular}

Tablo 2'de verilen malzeme ve fiyatları örnek prototipi oluşturmak için kullanılan malzeme ve fiyatlarıdır. Prototip ile gerçek ürün arasında Servo Motorların tork gücü bakımından kaynaklı bir maliyet olacağı için ürün fiyatında değişiklik olacaktır. Ürünün tam olarak gerçekleştirilmesi durumunda gerçek boyutlarda üretim durumunda tahmini maliyetin ne olacağ 1 ile ilgili de bir araştırma yapılarak Tablo 3'de gösterilmiştir.

Tablo 3. SLEGS yürüme engelli arabası gerçek boyut için tahmini fiyatlar

\begin{tabular}{|c|c|c|c|}
\hline Malzeme Adı & Adet & Adet Fiyatı & Toplam Fiyat \\
\hline Servo Motor & 6 & $300 \mathrm{TL}$ & 1800 TL \\
\hline Arduino Nano & 1 & $20 \mathrm{TL}$ & 20 TL \\
\hline Akü (12V, 33Ah) & 1 & $750 \mathrm{TL}$ & TL \\
\hline Slegs Özellikli Tekerlek & 2 & $250 \mathrm{TL}$ & 200 TL \\
\hline Kablolar & 40 & $5 \mathrm{TL}$ & \\
\hline Toplam & & $\mathbf{3 2 7 0}$ TL & \\
\hline
\end{tabular}

Ürünün gerçek boyutlarda üretimi söz konusu olduğunda en önemli unsurlarından birisi de akü ya da batarya malzemesi olacaktır. Bununla ilgili internette araştırma yapılmıştır. Günümüzde 
de yaygın olarak kullanılan engelli araçları için farklı kapasite ve güçte aküler olduğu tespit edilmiştir. Akülerin fiyatlarının da sahip oldukları özelliklere göre değiştiği görülmüş̧ür. Tablo 3 'de sunulan akü ise 12 volt olarak çalışmakta ve 33 Ah kapasiteye sahiptir. Yani oldukça güçlü ve uzun ömürlü bir aküdür. Bu araştırmada sunulan ürünün gerçek boyutlarda olması durumunda SLEGS bacakları ve sistemi rahatlıkla çalıştırabilir. Böyle tipte akü kullanılabileceği gibi farklı özelliklere sahip batarya sistemleri hatta güneş panelleri yardımıyla enerji sağlama gibi unsurlardan da faydalanılabilir.

$\mathrm{Bu}$ çalışmada önerilen prototipin belirli durumlarda nasıl performans sergileyeceği de Şekil 5 'de gösterilmiştir. Burada prototip bir merdiven çıkması durumunda tekerleklerin şekil değiştirme imkanı sayesinde merdivenleri başarı ile çıkabildiği görülmüştür.
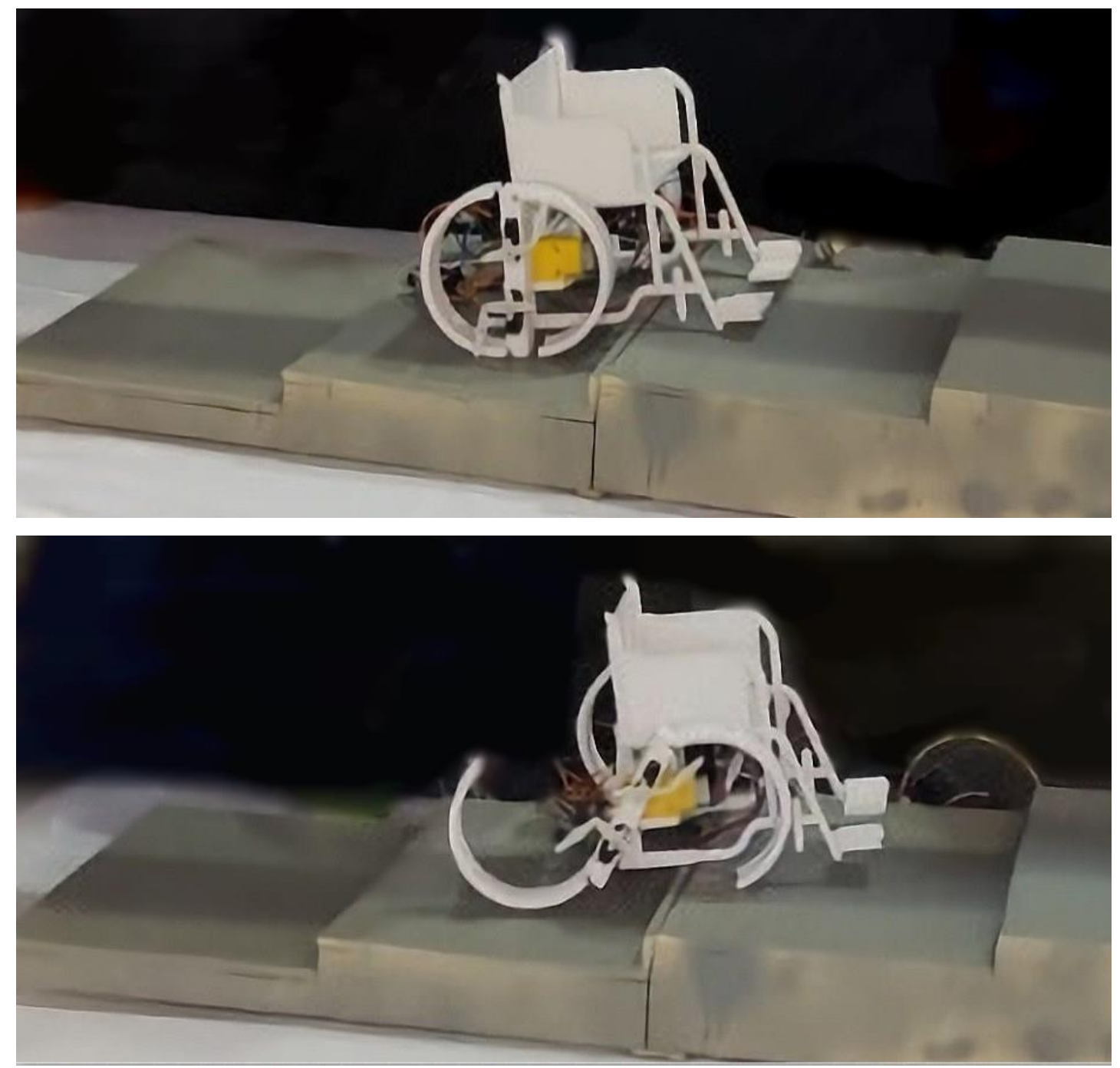

Şekil 5. SLEGS yürüme engelli arabası merdiven çıkma aşaması

Sonuç olarak, piyasada mevcut olan ve satılan ürünlerin özellik ve fiyatları ile karşılaştırma yapıldığında bu çalışmadaki ürünün avantajlı olduğu görülmektedir. Çünkü piyasadaki mevcut ürünlerde bir refakatçi yardımı ile tekerlekli arabalar sürülmektedir ve fiyatları da oldukça yüksektir. Bu çalışmada önerilen prototip ise bir refakatçi yardımına ihtiyaç duymamasından dolayı piyasadaki tüm ürünlerden avantajlıdır. Sistemin gerçek boyutlarda üretiminin yapılarak test 
aşamalarından geçmesi ve üretimi ile hem engelli bireylerin hayatlarının kolaylaşacağı hem de ülkemizin bu alandaki çalışmaları ile adından söz ettirebileceği düşünülmektedir.

\section{SONUÇLAR VE TARTIŞMA}

Engelli bireyler dünya nüfusunun yaklaşık \%15'lik bir kısmını teşkil etmekte ve bu sayı yaşlılık ve hastalıkların artması ile giderek artış göstermektedir. $\mathrm{Bu}$ artış ile birlikte engelli bireylerin yaşadığı güçlükler de artmaktadır. Özellikle yürüme engelli bireyler çevre şartları ile birlikte bu zorluklara maruz kalan bir kesimdir. Özellikle de merdiven gibi engebeli yerlerde yaşadıkları zorluklar yaşam standartlarında düşüşe neden olmaktadır. Bu sorunu gidermek için piyasada satışa sunulmuş ürünler olsa da bunların pahalı ve refakatçi gerektiren ürünler olması nedeni ile birçok engelli insan için kullanımı zordur. Bu çalışma bu güçlükleri ortadan kaldıracak yeni bir ürünün tasarımını gerçekleştirmek amacıyla yapılmıştır.

Merdiven gibi engebeli yerlerde tekerlekli sandalyenin çıkıp inebilmesi için SLEGS robot olarak bilinen robot tekerleklerinin engelli arabası için tasarımı Fusion 360 programı ile gerçekleştirilmiştir. Gerçekleştirilen 3 boyutlu tasarımın sadece tasarım olarak kalmaması için küçük bir prototipi de Ultimate 2+ yazıcısı ile çıktısı alınmıştır. Prototipin çalışması için Arduino Nano ve Servo motorlar kullanılmıştır.

Gerçekleştirilen tasarımın prototip ile birlikte kullanılabilirliği gösterilmiştir. $\mathrm{Bu}$ tasarımın gerçek boyutlarda üretime dönüştürülmesi ile birlikte yürüme engelli insanların yaşam şartlarının iyileşeceği düşünülmektedir. Aynı zamanda piyasada satışta bulunan ürünlerin ithal ve pahalı ürünler olması aynı zamanda refakatçi gerektiren ürünler olmasından dolayı bu çalışmada tasarlanan ürünün üretime geçirilmesi ile yerli ve milli bir ürün olma potansiyeline sahip olması bakımından da önemlidir.

Bundan sonraki çalışmalarda özellikle merdiven gibi yerlerde SLEGS tekerleklerin adım büyüklügünü ayarlama, kullanıcının bazı açısal bilgileri değiştirebileceği kontrol panelinin olması gibi yeni parametre ve donanımlar eklenebilir. Girişimcilik faaliyetleri kapsamında profesyonel bir üretim sistemi için gerekli çalışmalar yapılabilir. Ürünün gerçek boyutlu bir tasarımı yapılarak model üzerindeki testler gerçekleştirilebilir ve gerçek maliyetleri ortaya konabilir.

\section{KAYNAKÇA}

Altınok, M , Kars, M . (2010). “Tekerlekli Sandalye Kullanan Engellilere Yönelik Islak Mekân Düzenlemelerinde Fonksiyonel Yaklaşımlar”. Dumlupınar Üniversitesi Fen Bilimleri Enstitüsü Dergisi , (021), 107-120 .

Bekçi, B. (2012). "Fiziksel Engelli Kullanicilar İçin En Uygun Ulaşım Akslarının Erişebilirlik Açıdan İrdelenmesi: Bartin Kenti Örneği”. Bartın Orman Fakültesi Dergisi , 14 (1.Special Issue) , 26-36.

Çınar, H., Arslan, A., Öztürk, A., \& Bülbül, R. (2015). "Kamu Binalari: Engellilerin Donati Ve Mobilya Kullanimina Yönelik Yaşam Analizi”. Mühendislik Bilimleri ve Tasarım Dergisi, 3(3), 329-337.

Çınar, H., \& Erdem, H. E. (2008). "Yaşam Hakkı: Tekerlekli Sandalye Kullanıcılarının Konut İç Mekân Donatı Elemanları ve Mobilya Kullanımı”. Politeknik Dergisi, 11(2).

Feyzioğlu, G. (2013). Bedensel Engellilere Yönelik Kentsel Peyzaj Tasarim Kriterlerinin Ankara İli Kızılay Meydani ve İlişkili Caddelerinde İrdelenmesi. Yüksek Lisans Tezi. Ege Üniversitesi. İzmir. 
Kırd1, N., Keser, İ. (2019). "Yaşl1larda Kullanılabilecek Ergonomik Tekerlekli Sandalye Teknolojileri”. Türkiye Klinikleri Geriatri-özel Konular, 5(3), 86-90.

Öztabak, M. Ü. (2017). "Engelli Bireylerin Yaşamdan Beklentilerinin İncelenmesi”. FSM İlmî Araştırmalar İnsan ve Toplum Bilimleri Dergisi, (9), 355-375.

Saplığlu, M., \& Ünal, A. (2019). "Yürüme Engelli Bireyler İçin Kentiçi Ulaşımda Güzergah İyileştirme Önerisi: Pilot Bölge Çalışması”. Dümf Mühendislik Dergisi, 10(1), 289-299.

Sirel, B., Boyacıgil, O., Duymuş, H., Konaklı, N., Altunkasa, F., \& Uslu, C. (2012). "Çukurova Üniversitesi yerleşkesi açık alanlarının fiziksel engelliler bakımından ulaşılabilirliğinin değerlendirilmesi”. Çukurova Üniversitesi Mühendislik-Mimarlık Fakültesi Dergisi, 27(1), 53-72.

Soygüder, S. (2018). “Slegs Robot'un Tasarımı Ve 2b-Navigasyon Uygulaması”. Fırat Üniversitesi Mühendislik Bilimleri Dergisi, 30(1).

Sümbül, H., \& Yakut, Y. (2016). "Yürüme Engelli Bireyler Için Pedaldan Kumandalı Dikiş Makinelerinin Kumanda Bileklik Sistemi İle Kontrolü”. Politeknik Dergisi, 19(3), 245-249.

Tandoğan, O. (2017). "Evrensel tasarım kavramı: kentsel peyzaj ile ilgili örnekler”. Artium, 5 (2), 51-66.

True, E. M., \& Türel, H. S. (2013). "Yapılı Çevrelerin Fiziksel Engelliler Yönüyle Kullanılabilirliği: İzmir Kenti Örneği”. Artium, 1(1).

Turan, C. (2005). Güneş enerjisi takviyeli elektrikle çalışan tekerlekli sandalye. Yüksek Lisans Tezi, Makine Eğitimi Anabilim Dalı, Marmara Üniversitesi, İstanbul.

İnternet Kaynakları

https://teksaninovatif.com.tr/engelli-merdiven-cikma-inme-tasima-iletme-sistemi/.

10.12.2019 tarihinde erişilmiştir.

http://www.sinapsgrup.com/Urundetail.aspx? $\mathrm{Id}=25$. 10.12.2019 tarihinde erişilmiştir. 